\title{
Research on Business Model Innovation in the Era of Big Data
}

$$
\text { Feng Yahong }{ }^{1,} \text { a , Guo Yuli }{ }^{2,} \text {, }{ }^{*}
$$

${ }^{1}$ School of Management, Xi'an University of Science and Technology, Xian, Shaanxi, China

2 School of Management, Xi'an University of Science and Technology, Xian, Shaanxi, China

bemail-951940897@qq.com,

* Corresponding author Guo Yuli

Keywords: Big data, Business models, Innovation.

\begin{abstract}
The rapid development of information technology has led to explosive growth of data, and the era of big data has come. The use of big data and the development of Internet technology have made people realize that data is value and take various ways to tap into the economic value embodied in the data. This article combines the current economic development situation, analyzes the business model innovation, discusses the problems facing business model innovation in the era of big data, and puts forward feasible countermeasures and suggestions.
\end{abstract}

\section{Preface}

Mobile Internet has brought about tremendous changes to human life. The growth of data information volume is growing at a geometric rate. The development of the world economy has already entered the era of big data. The McKinsey Global Institute defines big data as "a collection of data that cannot be acquired, managed, and processed by traditional database software tools in a given period of time." The world produces various kinds of data every second. A large amount of data has not only promoted the development of computing technology, but also promoted the innovation of business models. In the era of big data, companies should overcome difficulties, use big data to gain competitive advantage, and formulate innovative development strategies.

\section{The connotation of big data and business model innovation}

\subsection{The meaning of big data}

At present, there is no authoritative definition for big data. As a background of social change, big data should basically include three layers of meaning: the pan-data of social life, the speed of data generation, and the scale of data. When people discuss big data, they know more about it through many basic characteristics. Most people summarize the characteristics of large data as four "V", that is, volume, variety, velocity, and veracity. For the concept of big data, there is no unified definition at present. The key to big data is to quickly acquire important information in rich data.

\subsection{The connotation and features of business model innovation}

The business model is based on the key resources and capabilities of the enterprise, and some participants in the industrial value chain to achieve value, create value, obtain value through transfer, and distribute value. Business model innovation refers to the innovative changes that companies provide to provide basic logic through value creation, injecting new business models into the system of business operations, and creating value for the company itself or society. In the era of big data, innovative business models of enterprises need to understand customer needs through data, and from the perspective of customers, design products and services that meet customer needs, so as to promote the economic efficiency of enterprises.

\section{Business model innovation in the era of big data}

\subsection{Value proposition innovation based on large data}


The value proposition of an enterprise refers to the value that an enterprise provides to its target consumers through the products or services it produces. Because of its own characteristics, big data has the potential to reach consumers indefinitely on the basis of analysis and excavation. This potential can not only analyze the real needs of consumers, but also subdivide consumers. Through the analysis of big data, the product can also be accurately and dynamically positioned. If the accumulated big data is analyzed in depth, this can facilitate the producer to adjust his own product or service in a timely manner. Not only can he gain profits but also can make Buyers get satisfactory products or services.

\subsection{Value discovery innovation based on large data}

Value discovery is to explore the existing value and opportunity, which makes the enterprise understand the real needs of the customers in a changing environment and make the important link of the products or services to meet the needs of the customers. However, the real needs of customers are dynamically changing. It is difficult to find straightforward analysis of structured or static historical data. However, with the emergence of big data, people are paying more and more attention to these problems. These difficult problems can be solved. The four "V" features of big data can comprehensively analyze the data. The current method is also more and more scientific. Enterprises can not only target their products in a targeted manner, but also can precisely define the customers who really need their products.

\subsection{Value creation innovation based on large data}

Value creation refers to the way companies conduct production and create value. The big data of enterprise business activities, the integration of big data activities into the value creation process, can find new direction and path of value creation, and have a great impact on value creation. Under the background of big data era, the value creation methods of enterprises have undergone great changes. Enterprises have changed from entity management to virtual management, or both have developed side by side; the space for creating value of enterprises has also undergone great changes, from the internal to the external. Through big data technology, the business process of a company can be redesigned, and even traditional business processes can be replaced by data activities, which will help improve its operational results.

\subsection{Innovation of value realization based on large data}

Value realization means that the value of creation must be distributed between the customer and the company to achieve their respective values. Many business model innovations are based on the fact that consumer demand for goods is essentially the use of goods rather than the ownership of goods. Then, if there is a business model that enables consumers to have the right to use goods and at the same time reduce the input costs of consumers for the goods, then this business model will also be recognized by consumers and the market. For example, with the help of big data, Internet advertising can calculate clicks and page views, and establish a direct link between advertising expenditure and advertising effectiveness.

\section{Problems of business model innovation in the era of large data}

\subsection{Big data analysis and processing technology}

The analysis and processing technology of big data is the core part of the business model innovation of big data. Big data analysis and processing technology is a core part of Big data for business model innovation. Google proposed a new technology system featuring distributed, namely, distributed file systems, distributed parallel computing, distributed data, and visualization technologies represented by big data processing technologies and hadoop distributed file system. These technologies are comparable. The low cost realizes the scale that the previous technology can't reach. However, these big data analysis and processing technologies only provide a basic framework for the application of the enterprise, but also require companies to use these technologies in combination with their own circumstances, so that enterprises are more competitive. 
In reality, not every company has a person skilled in mastering big data analysis technology.

\subsection{Data information security for big data}

In the face of huge data storage needs, although storage technologies are constantly evolving, the risk of information leakage and data loss is a major risk that companies have to consider and face in terms of information security. As big data mining analysis technology becomes more and more accurate and the application field continues to expand, personal privacy protection and data security become very urgent. For example, in September 2016, Yahoo announced an information disclosure problem involving 500 million global email accounts in 2014; in December 2016, Jingdong 12G's data leaked, including user names, passwords, emails, ID cards, phone numbers, etc. Big data contains a lot of private information. The occurrence of these events makes people aware of the importance of information security. If you do not attach importance to and protect these data, people's lives will be disturbed.

\subsection{Problems faced by laws and regulations}

With the development of information technology and the arrival of the era of big data, the collection and storage of data has become more convenient. The lack of regulation and supervision of emerging issues and the self-discipline of enterprises alone are not enough. When the definition of data usage rights is not clear and the standards for corporate self-discipline are different, it will inevitably infringe on the privacy and legal rights of users. China's laws and regulations regarding the protection of personal information and the cross-border flow of data are still inadequate. This factor has constrained the healthy development of the big data industry.

\section{The strategy of business model innovation in the era of big data}

\subsection{Technology introduction or selective technology outsourcing}

With the development of big data, there have been some "market research companies", such as: data collection companies, big data analysis companies, big data technology development companies. Because companies need to accumulate time to build their own big data databases, companies also need time to develop their own big data technicians. For big data analysis and processing technology problems, for companies with long-term and big data development plans, they can build their own large databases and train their own big data technologies and their professional talents; but for most companies with limited capabilities and limited funds In order to strengthen the application of big data technology, it can be introduced or outsourced through technology.

\subsection{Pay attention to data security}

For data security of big data, we must first strengthen the protection of personal information. In the protection of personal information, we must focus on regulatory data collection and data use. We can effectively help enterprises to establish a complete and integrated protection through the effective application of enterprise technical personnel. The system ensures the security of data information. In addition, we must strengthen the continuous monitoring and automatic analysis of all $\log$ data, and focus on improving anti-virus capabilities and the ability to prevent advanced persistent threats.

\subsection{Complete laws and regulations}

Perfecting laws and regulations must be combined with the actual conditions of China's legal construction. The improvement of laws and regulations is mainly reflected in personal privacy protection and data security. State agencies should clarify the authority and methods of using data by enterprises and formulate industry standards. If there is any illegal act, there will be a corresponding rights protection mechanism to protect personal rights. In addition, it is also necessary to combine the legal system with the rule of virtue and explore ways to make up for the imperfections in the legal system through such methods as industry self-regulation. 


\section{References}

[1] Yang Xin, Ma Shentong, Yang Jinbao, Research on Business Model Innovation under the Background of Big Data, Chinese Market, vol.43, pp. 36-38, 2016.

[2] Chen Peiling, Analysis of Business Model Innovation in the Era of Big Data, Money China (Academic Edition), vol.10, pp. 42, 2016.

[3] Zhou Nan, Tao Huiping, Li Haohao, On the innovation of business model in the context of big data, Enterprise Economy, vol.12, pp. 99-102, 2015.

[4] Jing Hao, Research on business model innovation in the era of big data, Science \& Technology Progress and Policy, vol.31, pp. 15-19, 2014.

[5] Li Wenlian, Xia Jianming, Business Model Innovation Based on "Big Data", China Industrial Economics, vol.05, pp. 83-95, 2013.

[6] Yi Jiabin, Xu Di, The Impact Mechanism of Big Data on Business Model Innovation: An Analytical Framework, Science \& Technology Progress and Policy, vol.35, pp. 15-21, 2018. 